\title{
Marketing Strategy of Green Agricultural Products based on Consumption Intention
}

\author{
Xueli Yang*, Ping Gong \\ School of Economics and Management, Heilongjiang Bayi Agricultural University, Daqing, \\ Heilongjiang, 163319, China
}

Keywords: Green agriculture; Green agricultural products; consumption intention

Abstract: With the improvement of people's living standards and the increasing emphasis on food safety, the green agricultural products industry has been growing. Based on the current achievements of Heilongjiang agricultural product brand and marketing, this paper analyzes the demand, price, channel, promotion and other aspects of green agricultural products from the perspective of consumer willingness and consumer behavior. Combined with the natural conditions of green agricultural products and based on the actual situation, this paper puts forward feasible marketing strategies for green agricultural products. On the one hand, the development of green agricultural products industry is conducive to creating a green and environmental business environment. On the other hand, it can further promote food safety, tap the local market demand, develop potential customers, and explore the combination of modern information technology and agricultural development. Some marketing strategies to adapt to the green agricultural products are put forward, such as expanding the docking of agricultural supermarkets, developing the community green agricultural products supermarkets, and the new development of mobile e-commerce.

\section{Introduction}

\subsection{Research background and significance}

China has made major decisions and arrangements on the work of "agriculture, rural areas and farmers", formulated the strategic plan for Rural Revitalization (2018-2022), and also made important instructions on the construction of agricultural product brand and agricultural product circulation system. In the report on the work of the government in 2019, it is proposed to "implement the project of maintaining agricultural products with geographical indications", and it is emphasized to adhere to the guiding ideology of giving priority to the development of agricultural and rural areas, to build specific brand and circulation system of agricultural products, to transform extensive management into refined and scientific management, and to implement modern agricultural management technology. 
In this context, this paper analyzes the advantages and current situation of the development of green agricultural products in Heilongjiang Province, and the difficulties faced by the construction of the circulation system. Starting with green agricultural products, we should ensure the growth of farmers' income, ensure the quality and safety of agricultural products, and meet the needs of consumers. We should explore a reasonable way to carry out the whole green model, which can be used for reference to promote the faster and greater development of green agricultural products industry from the perspective of green marketing and it is also conducive to building a green business environment and promoting food safety.

We should revitalize the development of characteristic agriculture, further promote the goal of agricultural product branding and marketization, and analyze the demand, price, channel, promotion and other aspects of green agricultural products from the perspective of consumer willingness and consumer behavior in combination with the current achievements of Heilongjiang agricultural product brand and marketing. Combined with the natural conditions of green agricultural products, and based on the actual situation, feasible marketing strategies for green agricultural products are put forward to explore the local market demand, provide accurate auxiliary information for its potential customers, and enter the target market, exploring the combination of modern information technology and agricultural development, and exploring marketing countermeasures and suggestions suitable for green agricultural products, so as to help the development of green agricultural products industry.

\subsection{Research status at home and abroad}

\subsubsection{Research status of green agricultural products abroad}

The research on marketing of green organic agricultural products abroad has a long time. American scholars focus on channel model selection, agricultural product pricing, consumer education, brand recognition and promotion. The marketing of organic agricultural products in the United States is mainly through the following two forms: supermarket marketing and agricultural products direct marketing. The exclusive counters with the certification mark of American green organic association in the supermarket are set up. Different from the conventional products, American green organic products have the unique market positioning. It is believed that the two factors of large supermarket traffic and high consumer recognition of organic agricultural products have become an important channel for the sales of organic agricultural products in the United States[1].

There are four marketing methods of green organic agricultural products in Europe. First, direct marketing. The producers of green organic agricultural products conduct marketing based on production bases in relevant geographical regions. This model can help to save the cost of taxes and management fees in the middle link of farmers, and at the same time, it can promote consumers to buy more cost-effective agricultural products. Second, marketing organic agricultural products in the form of natural food stores. The third is to adopt the retail marketing of agricultural products franchised supermarkets, which are often dominated by large-scale organic supermarkets. Fourth, the use of Organic Food Expo marketing.

Janssen and Hamm (2012) studied the important role of agricultural product brands, believing that agricultural product branding is conducive to the selection of green organic food in the market, 
and products with organic certification mark can bring greater market profits to producers. Organic label is a signal to consumers, indicating that certified organic products have good quality. Consumers have preferences and high willingness to pay for branded agricultural products. Therefore, it is conducive to the market promotion of the products to enhance the professionalism of the production and operation of green agricultural products, enhance the brand building of green agricultural products, optimize the classification of green agricultural products, standardize the product quality certification system, and paste the well-known organic certification mark trusted by consumers on the organic products [2].

\subsubsection{Research status of green agricultural products in China}

In recent years, the domestic consumers' consumption demand for safe and green agricultural products has been constantly increasing. The production of green agricultural products has gradually become a scale and categories are increasingly rich. The marketing of green agricultural products has made great progress. The development of green agricultural products industry is a long-term strategic task. We should master the market demand change, understand the demand development trend, effectively adjust the production and operation mode and operation objectives, and adapt to the market demand change and development situation. If green agricultural products cannot be sold in the market, profits cannot be made, resulting in the interruption of reproduction. Therefore, the primary link and task of green agricultural product marketing is its production, especially the implementation of green agricultural product branding, which plays an important role in improving the competitiveness of agricultural products [3]. Whether the green agricultural product marketing can be successfully implemented depends largely on whether the marketing channels are unblocked. Qiao Guanhua and Shi Xiuyun (2017) pointed out that green food is rich in varieties and has different characteristics, so there are different requirements for marketing channels. In terms of marketing channels, there is a dilemma at present. Due to the different nature of green products, there is a lack of circulation mode that can not only meet the general circulation of green food, but also meet the product characteristics [4]. The development of green agricultural products industry also needs the use of promotion strategies. Consumers are keen on green products. Businesses need to provide green products that satisfy consumers. They also need effective communication with each other. Producers can display green image, enhance public awareness and enhance consumer loyalty through advertising, holding green product fairs, conferences, news publicity and public relations activities [5]. With the continuous development of social economy, the production of green agricultural products is also developing, and the scale of consumption is expanding. It is necessary to build a green agricultural production base, a green agricultural supply chain management information platform, a green agricultural product processing center and a green agricultural product flow center. We should build supply chain, integrate information logistics technology, innovate management system and business model, relying on the closed supply chain management information platform of green agricultural products, tracking every link and process of green agricultural products from production to circulation, and promoting the healthy development of green agricultural products [6].

However, there are still many problems to be solved in the marketing of green agricultural products. The information between producers and consumers is not smooth, and there is a problem 
of product quality information asymmetry. The main reason is that consumers are hard to get sufficient information, and it is difficult to distinguish green agricultural products. This phenomenon is difficult to control illegal traders. The products are inferior, and fake and inferior products flood the market, seriously damaging the interests of consumers. At the same time, it strikes consumers against green products Confidence reduces the recognition of green brands. With the rise and development of Internet technology, only relying on traditional marketing methods cannot meet the market needs, many problems appear, such as the old marketing channel model, the lack of brand effect and so on. The final link of agriculture is sales, and the emergence of the Internet solves the problem of narrow sales channels. Di Jiayu (2018) pointed out that farmers can sell agricultural products through the Internet, which solves the problem of middlemen earning price difference, and is very helpful for the growth of sales volume, promoting the improvement of farmers' economic benefits. E-commerce marketing of green agricultural products faces huge market space [7].Therefore, we should develop online marketing platform for green agricultural products, strengthen brand building, expand and integrate the green food wholesale trading center, enhance the competitiveness of enterprises, increase government support, and take multiple measures to help the development and growth of green agricultural products industry.

\section{The Development of Organic Agricultural Products -A Case Study of Heilongjiang Province}

\subsection{Planting status of organic agricultural products}

Heilongjiang Province is famous for its black land. It continuously promotes green production, pays attention to the sustainable development of agriculture, and promotes the development of green organic food industry. Heilongjiang Province has taken the lead in developing green agricultural products and built a large area of green food production base. According to statistics, in 2018, the certified area of green food in Heilongjiang Province reached $49306 \mathrm{~km} 2$, and the certified area of organic food reached $4333 \mathrm{~km} 2$. In 2019, green agriculture will continue to be promoted. The planting area of green organic food will reach $53640 \mathrm{~km} 2$, and the production of green organic agricultural products will continue to grow.

\section{2 marketing status of organic agricultural products}

To play the role of the Internet, Heilongjiang has established 1600 Internet + agricultural demonstration bases, with an area of $2830 \mathrm{~km} 2$. We should make full use of the advanced technology of the Internet, innovate the marketing methods of agricultural products, and rely on the e-commerce platform to package and sell agricultural products, in order to achieve the effect of occupying the market rapidly. The marketing of organic agricultural products implements the brand planning and realizes the systematization of brand construction. For example, the rice of Wuchang City has achieved the effect of geographical indication. The brand value of Wuchang rice is up to 67.793 billion yuan, ranking the sixth in the comprehensive ranking of regional brands and the first in China's rice brands. The provincial government supports and encourages enterprises to broaden their international vision, guide them to explore the international market, carry out international product certification, and establish a raw material base for green agricultural products. The 
marketing of green agricultural products in Heilongjiang Province has entered the world. By 2019, there are 2700 green food labeling products and 600 organic food labeling products in Heilongjiang Province[8]. Traditional marketing mode, direct channel and agent marketing channel coexist, and the role of traditional marketing channel is obvious. The producers and farmers of organic agricultural products rely on the intermediary enterprises to transfer the agricultural products to the middlemen, such as market wholesalers, Secondary origin distributor, retailers or wholesalers of agricultural products, and then to channel members, and finally reach the hands of consumers [9].

\section{Investigation on Consumption Intention of Green Agricultural Products}

\section{1 descriptive analysis of questionnaires and samples}

Based on the results of this survey, this paper analyzes the current residents' consumption willingness, consumption status and purchase behavior of green agricultural products to understand consumer satisfaction, and then analyze the production and marketing of green agricultural products, so as to broaden the marketing channels of green agricultural products. The questionnaire is divided into two parts, including personal information statistics and questionnaire content. Personal information includes 7 items and 16 items. Generally speaking, the respondents are mainly female, 30-40 years old, with a monthly income of 3500-5000 yuan. Their education level is university and they live in urban areas.

Green agricultural products are mainly aimed at young and middle-aged people, which also requires a selective survey when conducting a questionnaire survey. This survey selects gender, age, occupation, monthly income, education level and residence to distinguish respondents. The reason is that the education level of consumers, occupation and monthly income are the main factors affecting the consumption ability. People of different ages hold different consumption views. Young and middle-aged people have a strong sense of self satisfaction in consumption, while the old and middle-aged people are used to frugal consumption. Therefore, age is one of the main reasons for the consumption gap. Consumers' attitudes towards green agricultural products are closely related to their education level and monthly income. Residence is also the influencing factor of consumer behavior on green agricultural products.

\section{2 investigation and analysis of residents' consumption intention and purchase behavior of green agricultural products}

With the improvement of people's living standards, people have a strong desire to consume green organic products. In terms of the factors that residents pay attention to when purchasing agricultural products and the factors that they first consider when purchasing green agricultural products, we found that consumers have the highest requirements for the quality of agricultural products, with the freshness accounting for $\mathbf{7 4 . 4 7 \%}$. Consumers are very concerned about the price, accounting for $63.83 \%$, which is unexpectedly higher than the proportion of pesticide residues, taste and other factors. Price has always been a concern of consumers when they consume. No matter what they buy, they should make clear the price before they pay first. Price is the key factor for a transaction. Price is also the core issue of marketing activities, which affects whether the final results of marketing activities can make up for all the input of the whole marketing activities, and whether the 
final marketing purpose can achieve the expected ideal. About $75 \%$ of the citizens are willing to pay less than 50\% more for green agricultural products in terms of the price of green agricultural products than that of ordinary agricultural products of the same kind. About $20 \%$ of the total number of citizens choose the price $50 \%$ - $80 \%$ higher than that of ordinary agricultural products. A small number of about $6 \%$ of citizens are still willing to pay $80 \%$ - $100 \%$ more than ordinary agricultural products for green agricultural products. Although consumers know that products are really good products, higher than ordinary products, they are not willing to spend too much price to buy. Therefore, when pricing products, we should fully consider this factor, and the pricing of green agricultural products should not be too high. Pricing is really what consumers care about most. We should look for a breakthrough in the marketing of green agricultural products from the perspective of price, and actively build an industrial operation model with sales pulling benefits.

Obtaining information is an important step in the process of consumer purchase decision. Only by making clear the channels of consumers' access to information and the decisive role of various channels, can enterprises accurately design product publicity programs, do a better job in publicity and increase sales. In terms of the way of purchasing green agricultural products and understanding information, and according to the analysis of the way of consumer information sources, it is found that media advertising push and video software promotion are no longer dominant. Promotion means such as free tasting activities and friend circle advertising account for about half. Personal source - recommendation of relatives and friends account for a large proportion. It can be seen that personal information sources account for a large proportion, indicating that in terms of agricultural product consumption, consumers believe more in the word-of-mouth propaganda of relatives and friends at present. In the fresh supermarket, agricultural trade market, wholesale market, direct selling stores, e-commerce platform retail and other forms of markets, the purchase amount of agricultural products, especially fruits and vegetables, is bound to be less for ordinary families. In order to ensure the freshness, most consumers choose fresh supermarket. Most of the consumers who are not willing to shop online are the elderly. First, the elderly have been used to shopping in supermarkets and farmer's markets for a long time. They are not willing to accept new things, change their lifestyle, and prefer to choose to buy at the farmer's stall.

The implementation of online shopping is based on the Internet. With the popularity of the Internet, more and more consumers begin to shop online. Enterprises also use the advantages of the Internet to let people know about products and provide online consulting services. However, for the sake of security, some people don't trust the network very much. According to the statistical data, it can be analyzed that the shorter the distribution distance is, the more qualified it is. If the distribution distance is shortened, the distribution time will be shortened and the freshness of fruits and vegetables will be improved, but the cost will be reduced. And the price will naturally be lower than that of other agricultural products. This is naturally very good for ordinary families. From this aspect, we can also see the sales advantages of local green agricultural products.

\section{Problems in The Marketing of Green Agricultural Products}

Traditional marketing model plays an indispensable role, but the increase of product prices will affect the frequency and quantity of consumers' purchase. Some farmers and producers are conservative in thinking, lacking the courage to accept new things, lacking innovation awareness, 
and relying too much on middlemen, which hinder the expansion of marketing channels for green agricultural products. Strengthening the training of new-type professional farmers and increasing the guidance of marketing personnel are the requirements to meet the market demand.

The storage of green agricultural products is insufficient and the distribution is scattered. Green agricultural products have special natural properties, which are easy to deteriorate and not easy to be preserved for a long time. If they are not stored and distributed in time and properly, the quality of products will be affected, especially green fresh agricultural products, which have higher requirements on storage conditions, and some have requirements on temperature zone. The fresh-keeping process of green agricultural products, the transportation process and the fresh-keeping degree of products reaching consumers are all important factors to be considered in marketing. At present, there are many problems such as small-scale farmers, weak distribution capacity, insufficient storage conditions, relying on wholesale market for sales, large losses and low added value, which easily lead to poor risk resistance ability of farmers, and no increase in production and income. The online purchase of green agricultural products is mostly based on families. Compared with the distribution for large supermarkets and wholesale markets, it also increases the transportation cost. The distribution route based on families is relatively scattered, and affected by different factors such as working hours, which often causes the phenomenon that consumers cannot collect in time and increases the difficulty of distribution.

\section{Expand the Marketing Mode of Green Agricultural Products}

\subsection{Expand the docking mode of agricultural supermarket and develop the community green agricultural products supermarket}

Agricultural super docking mode is an effective mode of green agricultural product marketing. First, the docking of agricultural Super enterprises can reduce the transaction cost, and change the transaction mode of agricultural products, which makes the cost of production factors obtained by the production enterprises from the outside continuously decrease. Second, the docking mode of agricultural Super enterprises can reduce the intermediate circulation links, shorten the supply chain of green agricultural products, reduce the circulation loss and the circulation cost. In addition, supermarkets can carry out standard inspection on specifications, quality, pesticide and fertilizer residues of green agricultural products, and handle them according to mandatory regulations. It can effectively monitor the processing and circulation of green agricultural products. Third, the mode of agricultural super docking is conducive to the stability of green agricultural production and the enthusiasm of planting producers. The mode of agricultural super docking can fix production by sales, ensure the sales channels of farmers, and solve the difficulties in the sales and storage of green agricultural products, especially fruits and vegetables. The expansion of agricultural super model can also promote the development of green agricultural products primary processing industry by sales, such as the demand of supermarket consumers for semi-finished products and small packaging. The sales channels of agricultural super docking model have certain stability, but also can stabilize the income of farmers to a certain extent, and the sales volume can be guaranteed.

We should expand the docking mode of agricultural supermarket, develop the docking supermarket of community green agricultural products, give full play to the professional 
characteristics of community supermarket which is more convenient and service-oriented. We also have to give full play to the advantages of distribution and customization to make green agricultural products, realizing the docking of producers and consumers of green agricultural products through specialized circulation channels, reducing the production and marketing chain of green agricultural products, and achieving the goal of producers, consumers and operators. The development trend of three win-win situation.

\subsection{Mobile e-commerce and new development of o2o model}

Ai Rui data shows that the number of mobile Internet users continues to increase. In March 2019, the number of mobile Internet monthly independent devices has reached 1.38 billion. The average daily online time per capita was 3.5 hours, an increase of 25\% year-on-year, and an increase of 42 minutes [10]. Mobile netizens install 52.3 apps per capita, increasing market opportunities and maintaining the growth advantage of APP distribution. The mobile terminal has surpassed the PC terminal, and the consumption prospect of mobile e-commerce market has increased. The main reason why $\mathrm{O} 2 \mathrm{O}$ mode can last forever is to combine the advantages of online and offline perfectly, give full play to the advantages of Internet, such as cross region, boundless, mass information and mass users, complete the docking with physical stores, and realize the landing of Internet. Let consumers get online preferential transactions and offline services, which is conducive to promoting online users and offline goods and services transactions. O2O model can be used to conduct intuitive statistics and tracking evaluation on the marketing effect of merchants. The promotion effect of traditional marketing model usually has unpredictable limitations, and $\mathrm{O} 2 \mathrm{O}$ model can effectively avoid this. This mode combines online orders with offline consumption, and all consumption behaviors can be accurately counted, which can attract businesses and provide consumers with more and better products and services. Mobile e-commerce has more advantages in combination with $\mathrm{O} 2 \mathrm{O}$, which can become an effective way of marketing green agricultural products.

In the age of $5 \mathrm{G}$ communication, mobile e-commerce is more flexible and has more prominent advantages. Mobile communication technology can accurately position each participating system in the e-commerce value chain, including businesses and users, to help find more potential customers and obtain the required services. Through the statistical summary of various data of consumers in e-commerce, we can screen and analyze the consumer preference and consumption ability of green agricultural products, achieve the target customer positioning, establish long-term contact with the target customer group and provide marketing services in combination with Wechat marketing, small procedures, app and other ways.In addition, we should develop B2B and B2C models. Finally, we should strengthen conference sales, actively participate in fairs and fairs, expand the publicity of green agricultural products, actively seek target customers and target markets, and expand channels for the marketing of green agricultural products in our city.

\section{Acknowledgements}

The paper was supported by Fund projects: Daqing philosophy and social science planning research project (No.DSGB2019110) research findings. 
Heilongjiang Bayi Agricultural University Support Program for San Heng San Zong, Project No.: TDJH201811

\section{References}

[1]Meier M S, Stoessel F, Jungbluth N, et al. Environmental impacts of organic and conventional agricultural products - Are the differences captured by life cycle assessment? Journal of Environmental Management, 2015(2):193-208.

[2]Janssen M, Hamm U. Product labelling in the market for organic food: Consumer preferences and willingness-to-pay for different organic certification logos. Food Quality and Preference, 2012(1):1-22.

[3]Qitao Hu. Green food market development and marketing strategies. Anhui Agricultural Science 2007 (28): 9060-9061.

[4]Guanhua Qiao, Xiuyun Shi. Suggestions on the optimization of green food marketing channels in Heilongjiang. Business economy, 2017 (9): 8-9 + 28.

[5]Guoliang Zhang, Yingui Zhang. Brand marketing strategy analysis of green agricultural products. Chinese and foreign entrepreneurs, 2017 (4): 50-52.

[6]Xiaojing Liu, Na Ma, Jianfeng Zheng. Analysis on the construction of closed supply chain of green agricultural products. Modern agricultural science and technology, 2011 (24): $391+394$.

[7]Jiayu Di, Xi Wang, Li Zhao. Research on the development path of green food industry from the perspective of marketing innovation. Business economy, 2018 (09): 57-58 + 142.

[8]People's Network September 11, 2019.

[9]Yinyan Wang. Current situation and Countermeasures of agricultural informatization development in Lishui City. Agricultural network information 2018 (01): 95-98.

[10]IResearch. China Internet traffic quarterly analysis report, 2019 (3). 